\title{
Mortalin Inhibition in Experimental Parkinson's Disease
}

\author{
Davide Chiasserini, PhD, ${ }^{1,2}$ Alessandro Tozzi, PhD, ${ }^{1,2}$ Antonio de lure, PhD, ${ }^{1,2}$ Michela Tantucci, PhD, ${ }^{1}$ Federica Susta, PhD, ${ }^{3}$ \\ Pier Luigi Orvietani, MSc, ${ }^{3}$ Keizo Koya, PhD, ${ }^{4}$ Luciano Binaglia, PhD, ${ }^{3}$ and Paolo Calabresi, $\mathrm{MD}^{1,2 *}$ \\ ${ }^{1}$ Clinica Neurologica, Università degli studi di Perugia, Ospedale S. Maria della Misericordia, Perugia, Italy \\ ${ }^{2}$ Fondazione S. Lucia-I.R.C.C.S., Rome, Italy \\ ${ }^{3}$ Dipartimento di Medicina Interna, Sezione di Biochimica, Università di Perugia, Perugia, Italy \\ ${ }^{4}$ Synta Pharmaceuticals Corp., Lexington, Massachusetts, USA
}

\begin{abstract}
Among heat shock proteins, mortalin has been linked to the pathogenesis of Parkinson's disease. In the present work a rat model of Parkinson's disease was used to analyze the expression of striatal proteins and, more specifically, mortalin expression. The possible involvement of mortalin in Parkinson's disease pathogenesis was further investigated by utilizing an electrophysiological approach and pharmacological inhibition of mortalin in both the physiological and the parkinsonian states. Proteomic analysis was used to investigate changes in striatal protein expression in the 6-hydroxydopamine rat model of Parkinson's disease. The electrophysiological effects of MKT-077, a rhodamine-123 analogue acting as an inhibitor of mortalin, were measured by field potential recordings from corticostriatal brain slices obtained from control, sham-operated, and 6-hydroxydopamine-denervated animals. Slices in the presence of rotenone, an inhibitor of mitochondrial complex I, were also analyzed. Proteomic analysis revealed down-
\end{abstract}

regulation of mortalin in the striata of 6-hydroxydopamine-treated rats in comparison with sham-operated animals. MKT-077 reduced corticostriatal field potential amplitude in physiological conditions, inducing membrane depolarization and inward current in striatal medium spiny neurons. In addition, we observed that concentrations of MKT-077 not inducing any electrophysiological effect in physiological conditions caused significant changes in striatal slices from parkinsonian animals as well as in slices treated with a submaximal concentration of rotenone. These findings suggest a critical link between mortalin function and mitochondrial activity in both physiological and pathological conditions mimicking Parkinson's disease. (C) 2011 Movement Disorder Society

Key Words: mortalin; Parkinson's disease; 6-hydroxydopamine; rotenone; mitochondria; heat shock protein
Distinctive neuropathological features of Parkinson's disease (PD) include neuronal degeneration of the substantia nigra pars compacta (SNpc), consequential denervation of dopaminergic terminals in the nucleus

*Correspondence to: Professor Paolo Calabresi, Clinica Neurologica, Università degli Studi di Perugia, Ospedale S. Maria della Misericordia, 06156 Perugia, Italy; calabre@unipg.it

Relevant conflicts of interest/financial disclosures: Nothing to report. The present work was supported by grants from the European Community (EC) contract number 222918 (REPLACES) FP7-Thematic priority HEALTH (to P.C.), Progetto Strategico 2007 (to P.C.), Progetti

Finalizzati Multicentrici Programma Neuroscienze Compagnia di San Paolo (to P.C.), and Progetti di Ricerca di Interesse Nazionale (PRIN 2008; to P.C.).

Full financial disclosures and author roles may be found in the online version of this article.

Received: 11 November 2010; Revised: 20 December 2010; Accepted: 29 December 2010

Published online 3 May 2011 in Wiley Online Library

(wileyonlinelibrary.com). DOI: 10.1002/mds.23647 striatum, and cytoplasmic protein inclusions named Lewy bodies (LBs). ${ }^{1}$ Decreased activity of mitochondrial complex I has been observed in the $\mathrm{SNpc}$ of $\mathrm{PD}$ patients. $^{2-4} \mathrm{PD}$ models utilizing complex I inhibitors such as rotenone and 1-methyl 4-phenyl 1,2,3,6-tetrahydropyridine (MPTP) replicate characteristics of the disease, including production of reactive oxygen species (ROS) and nigrostriatal dopaminergic cell death. ${ }^{5-9}$ Complex I activity is also reduced following in vitro ${ }^{10}$ and in vivo ${ }^{11}$ application of 6-hydroxydopamine (6OHDA), a neurotoxin that has been widely used to generate a well-characterized unilateral rodent model of PD.

Heat shock proteins (HSPs) have been implicated in the molecular pathogenesis of neurodegenerative diseases considering their pivotal role as cellular sensors of various types of stress-related events: mitochondriarelated neurodegeneration, ${ }^{12}$ conformation and folding chaperone activity on newly formed proteins, ${ }^{13}$ 
trafficking of target proteins across membranes, ${ }^{14}$ escorting misfolded proteins to the proteasome, ${ }^{15} \alpha$ synuclein fibril and oligomer assembly, ${ }^{16}$ and maintenance of neuronal homeostasis after mitochondrial insults. $^{17}$

Mortalin, one of the members of the HSP70 protein family (also called stress 70 protein, heat shock protein 75 , and glucose-regulated protein $75 \mathrm{kDa}$ ), is a multifaceted protein with a major role in mitochondrial proteins importing and folding. ${ }^{18}$ Recent studies on its role in neuronal cells and neurodegenerative diseases have shown that downregulation of mortalin is mitochondrial specific in mesencephalic cells treated with rotenone, ${ }^{19}$ although its overexpression is associated with recovery of mitochondrial function and reduction of free-radical generation in the rat brain. ${ }^{20}$ In addition, mortalin has been linked to PD pathogenesis because of its decline both in the brain of histopathologically verified PD and in cellular models of PD. 19,21

Mortalin interacts with the PD-related proteins DJ-1 and $\alpha$-synuclein in cultured cells, ${ }^{22,23}$ and its interactions are susceptible to oxidative stress. Furthermore, mortalin was found to be covalently modified by dopamine following exposure of isolated rat brain mitochondria to the dopamine quinone, ${ }^{24}$ and its protein levels were selectively decreased in cells or isolated mitochondria exposed to dopamine toxicity. ${ }^{25}$ Thus, it is possible that loss of this protein could have a major impact on the import and incorporation of key mitochondrial proteins, particularly in times of stress. However, the exact role of mortalin in PD pathogenesis remains to be elucidated.

The first aim of the present work was to confirm the pathophysiological role of mortalin in experimental PD. To achieve this objective, we used the 6-OHDA rat model of $\mathrm{PD}$, causing both $\mathrm{DA}$ denervation and altered mitochondrial activity, and we used a proteomic approach to study changes in mortalin expression and modifications of global protein expression in 6-OHDA-treated animals compared with sham-operated controls. A second goal of the study was to investigate the possible physiological function of mortalin in basal ganglia neuronal activity. For this reason, we used electrophysiological recordings from control striatal neurons coupled with the application of the rhodamine-123 analogue MKT-077, a substance able to directly bind mortalin, modifying its secondary and tertiary structures until reaching its complete inactivation. ${ }^{26,27}$

The third aim of our study was the characterization of the acute inhibition of mortalin activity in experimental models of PD involving impaired mitochondrial activity. To address this issue, we investigated the acute electrophysiological effects of MKT-077 in the 6-OHDA in vivo model of PD as well as in the presence of known concentrations of the mitochondrial complex I inhibitor rotenone. The latter experiments were designed to reveal whether a low concentration of MKT-077 that does not affect per se neuronal electrical activity under control condition is able to produce detectable changes in models of mitochondrial impairment mimicking PD, such as in the in vivo 6-OHDA model and the in vitro model of rotenone.

\section{Materials and Methods}

\section{Experimental Model}

One- to 3-month-old male Wistar rats (Harlan, Italy) were used in this study. Experiments were carried out in conformity with the European Communities Council Directive of November 1986 (86/609/ECC). A total of 12 rats were used for proteomic analysis, whereas 20 animals were used for electrophysiological experiments. To obtain unilateral nigrostriatal lesions, 6 rats (anesthetized with $45 \mathrm{mg} / \mathrm{kg}$ body wt chloral hydrate) were injected with 6 -OHDA $(12 \mu \mathrm{g} / 4 \mu \mathrm{L}$ of saline containing $0.1 \%$ ascorbic acid; Sigma-Aldrich, Milan, Italy) via a Hamilton syringe into the medial forebrain bundle ${ }^{28}$ using stereotaxic coordinates. ${ }^{29}$

Six control rats were sham-operated and injected with saline containing $0.1 \%$ ascorbic acid. Fifteen days after injection, rats were tested with $0.05 \mathrm{mg} / \mathrm{kg}$ subcutaneous apomorphine, and contralateral turns were counted for 40 minutes. Only rats that consistently made at least 200 contralateral turns were used in the study, ${ }^{28}$ according to previous evidence demonstrating that rats meeting this screening criterion exhibit more than $95 \%$ depletion of striatal dopamine. ${ }^{30}$ Rats were used for experiments 45 days after the lesion. Striata were quickly dissected and snap-frozen in liquid nitrogen. Samples were stored at $-80^{\circ} \mathrm{C}$ until assayed. The severity of the lesion was confirmed ex post by performing immunohistochemical assays for striatal and nigral tyrosine hydroxylase. ${ }^{28}$

\section{Comparative Proteomics}

Frozen striata were homogenized by tip sonication at $0^{\circ} \mathrm{C}(5 \times 20$ seconds, with 30 -second intervals $)$ in 1 $\mathrm{mL}$ of lysis buffer ( $7 \mathrm{M}$ urea, $2 \mathrm{M}$ thiourea, $4 \%$ CHAPS, $0.5 \%$ Triton X-100, $40 \mathrm{mM}$ Tris base, 50 mM DTT) supplemented with $5 \mu \mathrm{L}$ of protease inhibitor cocktail (Sigma-Aldrich, Milan, Italy). Samples were then centrifuged for 30 minutes at $14,000 \mathrm{~g}$ at room temperature, aliquoted, and frozen at $-80^{\circ} \mathrm{C}$. Proteins were quantified according to Bradford, using bovine serum albumin as standard. ${ }^{31}$ Aliquots of supernatant containing $0.3 \mathrm{mg}$ of protein were separated by two-dimensional electrophoresis (2DE) as previously described. ${ }^{32}$ Image analysis was carried out with PDQuest software version 7.2. Matching data from PDQuest were exported in SPSS version 16.0 to assess statistical significance of differentially expressed spots. Because the distribution of data was skewed, the 


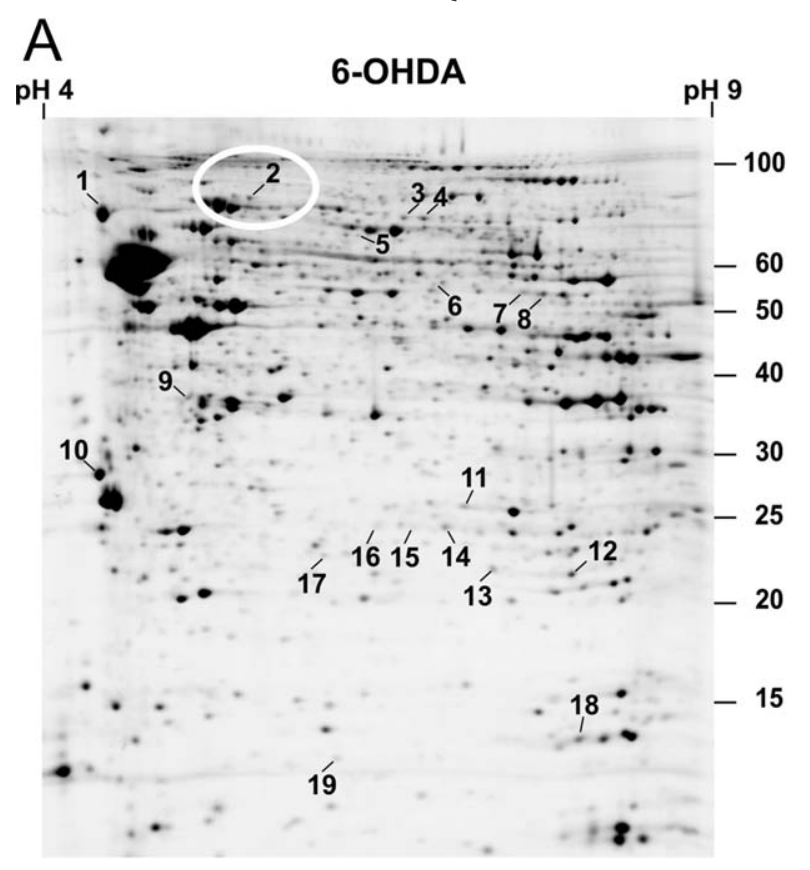

$\mathrm{B}$

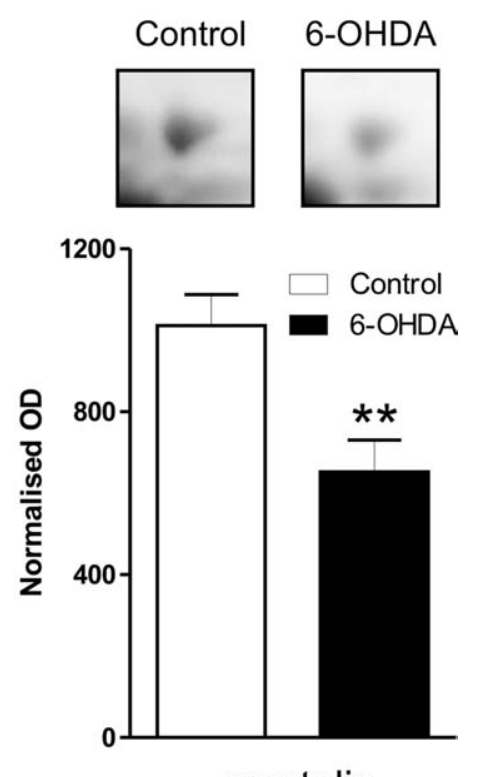

FIG. 1. Mortalin is decreased in the 6-OHDA rat PD model. A: Two-dimensional electrophoresis (2DE) map of proteins extracted from 6-OHDAtreated striata (white circle, mortalin spot). B: Detail of the spot identified as mortalin in sham-operated rats (control) and 6-OHDA-treated rats (6OHDA); the histogram of the normalized optical density of the mortalin spot in the two experimental groups is reported below. The 6-OHDA striatum shows a significant reduction in mortalin $\left({ }^{*} P<.05\right)$.

Mann-Whitney test was used to compare experimental groups. Selection criteria for undergoing protein identification process were: minimum optical density fold change of 1.5 with $P<.05$. Polypeptide spots were cut, destained, and trypsin-digested, as previously described. ${ }^{32}$ Identification of proteins was performed as previously described ${ }^{33}$ by tandem mass spectrometry (LC-MS/MS) using an LCQ X Deca plus instrument (Thermo Scientific, San Jose, CA). Database searching was carried out with Mascot search engine version 2.2.

\section{Electrophysiology}

Corticostriatal slices were prepared and maintained as previously reported. ${ }^{28,34}$

A single slice (thickness, $270 \mu \mathrm{m}$ ) was transferred to a recording chamber and submerged in continuously flowing Kreb's solution $\left(34^{\circ} \mathrm{C} ; 2.5-3 \mathrm{~mL} / \mathrm{min}\right)$ equilibrated with a $95 \% \mathrm{O}_{2}-5 \% \mathrm{CO}_{2}$ gas mixture. The composition of the solution was $126 \mathrm{mM} \mathrm{NaCl}, 2.5$ $\mathrm{mM} \mathrm{KCl}, 1.2 \mathrm{mM} \mathrm{MgCl} 2,1.2 \mathrm{mM} \mathrm{NaH} \mathrm{PO}_{4}, 2.4$ $\mathrm{mM} \mathrm{CaCl}_{2}, 10 \mathrm{mM}$ glucose, and $25 \mathrm{mM} \mathrm{NaHCO}_{3}$.

Electrodes for extracellular recordings of field potentials (FPs) were filled with $2 \mathrm{~mol} / \mathrm{L} \mathrm{NaCl}$ (15-20 M 2 ). A corticostriatal FP was evoked every 10 seconds by a bipolar electrode connected to a stimulator unit (Grass Telefactor, West Warwick, RI). Intracellular recordings of striatal medium spiny neurons (MSNs) were obtained by using sharp microelectrodes backfilled with $2 \mathrm{~mol} / \mathrm{L} \mathrm{KCl}$ (30-60 M $\Omega$ ). For patch-clamp recordings, neurons were visualized using differential interference contrast (Nomarski) and infrared microscopy (Olympus Europa GMBH, Hamburg, Germany). Intracellular solution for whole-cell recordings (Vhold $=-80 \mathrm{mV}$ ) was $145 \mathrm{mM} \mathrm{K}^{+}$gluconate, $0.1 \mathrm{mM}$ $\mathrm{CaCl}_{2}, 2 \mathrm{mM} \mathrm{MgCl}$, $0.1 \mathrm{mM}$ EGTA, $10 \mathrm{mM}$ Hepes, $0.3 \mathrm{mM}$ GTP, and $2 \mathrm{mM} \mathrm{Mg-ATP}$, adjusted to a $\mathrm{pH}$ of 7.3 with $\mathrm{KOH}$. Only neurons electrophysiologically identified as spiny neurons were considered for the experiments. Details on setup configuration for extracellular, intracellular, and patch clamp have been previously published. ${ }^{35}$

Off-line analysis was performed using Clampfit 10 (Molecular Devices, Sunnyvale, CA) and GraphPad Prism 3.0 (GraphPad Software, La Jolla, CA) software. Analysis of variance and Bonferroni's post hoc test were used for statistical analysis. Values given in the figures and text are mean \pm standard error of the mean. The significance level was established as $P<$ $.001(* * *)$. Rotenone was obtained from SigmaAldrich (Milan, Italy). MKT-077 was kindly provided by Synta Pharmaceuticals. Rotenone and MKT-077 solutions were prepared by dissolving powders in water or dimethylsulfoxide.

\section{Results}

\section{Differential Analysis of Protein Expression}

A representative proteome pattern of striatum isolated from 6-OHDA-treated rats and control shamoperated rats (CS) is shown in Figure 1A. After automatic spot detection, an average of 1203 polypeptides 
C H I A S S R I N I E T A L .

TABLE 1. Proteins differentially expressed in 6-OHDA-treated rats with respect to sham-operated controls

\begin{tabular}{|c|c|c|c|c|c|c|c|c|c|c|}
\hline Spot ID & Protein name & Score & $\begin{array}{c}\text { Sequence } \\
\text { coverage } \\
(\%)\end{array}$ & $\begin{array}{l}\text { Swiss } \\
\text { Uniprot } \\
\text { code }\end{array}$ & $\begin{array}{l}\text { Theoretical } \\
\text { MW (kDa) }\end{array}$ & $\begin{array}{l}\text { Experimental } \\
\mathrm{MW}(\mathrm{kDa})\end{array}$ & $\begin{array}{l}\text { Theoretical } \\
\text { pl }\end{array}$ & $\begin{array}{l}\text { Experimental } \\
\mathrm{pl}\end{array}$ & $\begin{array}{l}\text { Fold } \\
\text { change }\end{array}$ & $P$ value \\
\hline & Redox processes & & & & & & & & & \\
\hline 2 & Mortalin (stress-70 protein) & 261 & $12 \%$ & P48721 & 74 & 73 & 5.97 & 6 & -1.5 & .0065 \\
\hline 13 & Glutathione S-transferase P & 235 & $19 \%$ & P04906 & 23.6 & 21.1 & 6.89 & 7.3 & -1.5 & .0042 \\
\hline 12 & Glutathione S-transferase P & 314 & $32 \%$ & P04906 & 23.6 & 21.6 & 6.89 & 7.7 & 1.2 & .0641 \\
\hline 18 & $\begin{array}{l}\text { Cyclophilin A } \\
\text { Metabolic and energy pathways }\end{array}$ & 369 & $42 \%$ & P10111 & 17.8 & 12.7 & 8.34 & 7.8 & -1.4 & .0032 \\
\hline 11 & Phosphoglicerate mutase 1 & 392 & $46 \%$ & P25113 & 28.9 & 25.4 & 6.67 & 7.1 & -1.5 & .0195 \\
\hline 16 & Triosephosphate isomerase & 242 & $35 \%$ & P48500 & 27.3 & 23.1 & 6.89 & 6.7 & -1.9 & .0076 \\
\hline 15 & Triosephosphate isomerase & 281 & $34 \%$ & P48501 & 27.3 & 23.2 & 6.89 & 6.9 & -2.3 & .0002 \\
\hline 14 & Triosephosphate isomerase & 338 & $38 \%$ & P48502 & 27.3 & 23.5 & 6.89 & 7 & -1.7 & .0024 \\
\hline 7 & 4-aminobutyrate aminotransferase & 705 & $37 \%$ & P50554 & 57.6 & 54.7 & 8.15 & 7.4 & -2.1 & .0038 \\
\hline 8 & $\begin{array}{l}\text { 4-aminobutyrate aminotransferase } \\
\text { Signaling }\end{array}$ & 666 & $33 \%$ & P50554 & 57.6 & 54.8 & 8.15 & 7.5 & -1.3 & .1159 \\
\hline 10 & 14-3-3 protein epsilon & 356 & $25 \%$ & P62260 & 29.1 & 30 & 4.63 & 4 & -2 & .0313 \\
\hline 9 & $\begin{array}{l}\text { Serine/threonine-protein phosphatase } \\
2 \mathrm{~A} \text { catalytic subunit beta isoform }\end{array}$ & 414 & $35 \%$ & P62716 & 36.1 & 36.9 & 5.21 & 5.4 & -1.7 & .0275 \\
\hline 6 & $\begin{array}{l}\text { Calcium/calmodulin-dependent } \\
\text { protein kinase type II } \\
\text { Cytoskeletal proteins }\end{array}$ & 118 & $5 \%$ & P11275 & 54.6 & 54.3 & 6.61 & 7 & 1.3 & .0073 \\
\hline 1 & $\begin{array}{l}\text { Neurofilament protein } \mathrm{L} \\
\text { Other functions }\end{array}$ & 660 & $47 \%$ & P19527 & 68 & 61 & 4.63 & 4.7 & -1.6 & .0293 \\
\hline 5 & Seryl-tRNA synthetase, cytoplasmic & 322 & $19 \%$ & Q6P799 & 59 & 63.6 & 5.86 & 6.6 & 2 & .0275 \\
\hline 3 & Syntaxin binding protein 1 & 452 & $23 \%$ & P61765 & 67.9 & 68.7 & 6.49 & 6.9 & 1.3 & .0428 \\
\hline 4 & Syntaxin binding protein 1 & 487 & $28 \%$ & P61765 & 67.9 & 69.1 & 6.49 & 7 & 1.6 & .0484 \\
\hline 19 & Ubiquitin-conjugating enzyme E2 N & 78 & $40 \%$ & Q9EQX9 & 17.1 & 11.2 & 6.13 & 6.4 & -1.5 & .0576 \\
\hline 17 & $\begin{array}{l}\text { Proteasome subunit beta } \\
\text { type- } 4 \text { precursor }\end{array}$ & 77 & $9 \%$ & P34067 & 29.3 & 20.9 & 6.45 & 6.4 & -1.5 & .0103 \\
\hline
\end{tabular}

Reported for each protein are Mascot identification score, sequence coverage, the Uniprot code, theoretical and experimental molecular mass and isoelectric point, fold change, and Mann-Whitney $P$ value.

were found in gels of both groups. After manual editing and matching, an average of $405 \pm 24$ spots were detected in the 6-OHDA group, whereas the valid spot number was $421 \pm 18$ in the CS group. The coefficient of variation $(\mathrm{CV})$ of individual spot volumes was $28.2 \%$ in the 6 -OHDA group and $33.39 \%$ in the CS group, with the global matching value being about $30.6 \%$.

Following the selection criteria described above, 19 polypeptides were found to be differentially expressed in 6-OHDA and sham-operated rats, 5 of these being upregulated and 14 downregulated in the 6-OHDA group. Proteins whose abundance was modified by the 6-OHDA treatment were grouped according to their most relevant role: (1) metabolism, mainly glycolytic enzymes, (2) response to stress, and (3) signalingrelated proteins. The complete list of differentially expressed proteins is reported in Table 1. Among the downregulated polypeptides, neurofilament protein $\mathrm{L}$ expression in 6-OHDA-treated rats accounted for $50 \%$ of that observed in controls. Considering the role of this protein in maintaining neuronal shape and structure, such a decrease might be considered a signal of neurodegeneration. ${ }^{36}$ Impaired glycolytic activity, evidenced by the downregulation of the glycolytic enzymes triosephosphate isomerase and phosphoglycerate mutase suggests that impairment of glycolytic activity parallels the failure of the mitochondrial respiratory chain occurring after 6-OHDA injection. ${ }^{37}$ Three proteins involved in stress response were identified as differentially expressed. Among them, 1 spot with a molecular mass of $73 \mathrm{kDa}$ and an isoelectric point of 6 was identified as mortalin. Differential expression analysis showed a significant $(P<.05)$ decrease in mortalin in 6-OHDA-treated rats, with an average ratio of 1.5 between hemiparkinsonian rats and sham-operated controls. The other 2 proteins in the stress response group were glutathione-S-transferase $p$ (GST-p) and cyclophilin A. GST-p was identified in 2 spots differing for their isoelectric point. A statistically significant decrease in the acidic isoform (pI 7.3) was observed, whereas the small increase in the basic form (pI 7.7) did not reach statistical significance. By calculating the ratio between the acidic and basic forms in each analyzed sample, a statistically significant decrease $(P<$ .05, Mann-Whitney test) was observed in 6-OHDAtreated striata compared with controls. Cyclophilin A was identified in 4 spots exhibiting the same molecular weight but different isoelectric point values, presumably from post-translational modification processes. ${ }^{38}$ The 
A

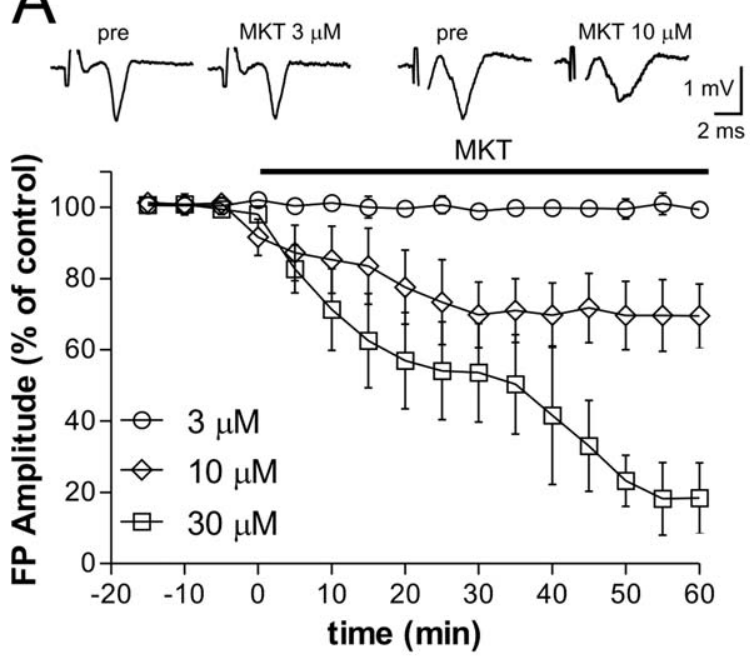

C patch clamp recording

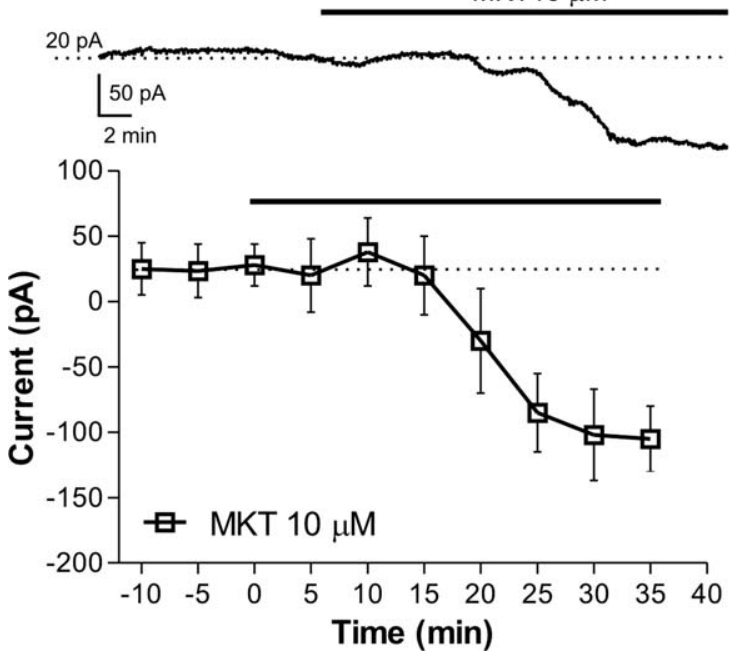

B MKT $10 \mu \mathrm{M}$

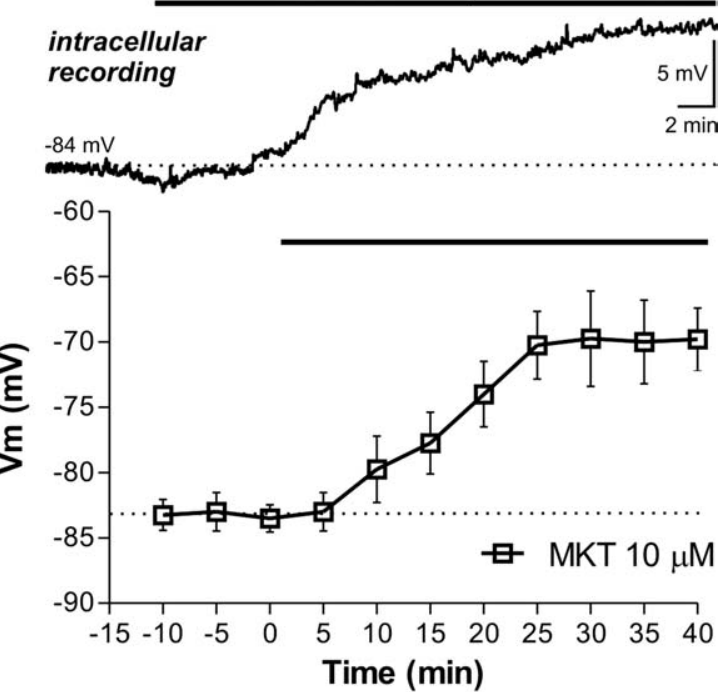

D

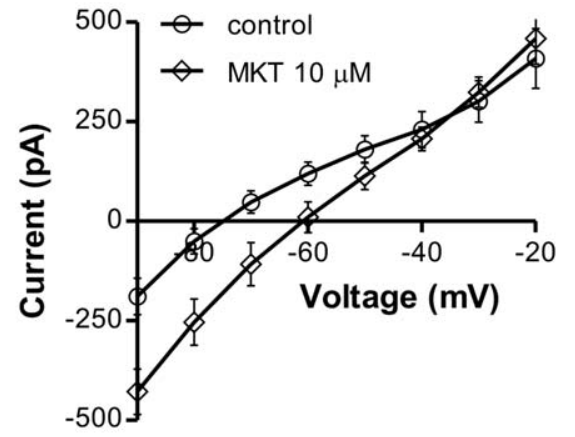

FIG. 2. The mortalin inhibitor MKT-077 reduces corticostriatal field potential amplitude and produces membrane depolarization/inward current in striatal medium spiny neurons. A: Example traces of corticostriatal field potentials (FPs) recorded in control conditions and in the presence of two doses of the mortalin inhibitor MKT-077. Time course showing the mean FP amplitude, as percentage of control, recorded in the presence of 3, 10, and $30 \mu \mathrm{M}$ MKT-077. Note that a bath application of $3 \mu \mathrm{M}$ MKT-077 did not produce any effect, whereas 10 and $30 \mu \mathrm{M}$ MKT-077 significantly reduced the FP amplitude. B: Representative trace of an intracellular recording showing the membrane depolarization of a medium spiny neuron (MSN) in the presence of $10 \mu \mathrm{M}$ MKT-077. Graph showing the time course of the mean membrane potential amplitude of MSNs recorded in control conditions and in the presence of $10 \mu \mathrm{M}$ MKT-077. C: Representative trace recording of the inward current obtained from an MSN in a whole-cell patch clamp. The time course shows the mean inward current produced after bath application of $10 \mu \mathrm{M}$ MKT-077. D: Current voltage plot showing that $10 \mu \mathrm{M}$ MKT-077 produced an inward current that reversed at about $-35 \mathrm{mV}$.

acidic isoform with a pI of 7.8 was significantly downregulated in the ipsilateral striata of 6-OHDA-lesioned rats compared with controls, whereas the expression of the other isoforms did not change significantly.

\section{Effect of Mortalin Inhibition on Corticostriatal Slice Preparations}

After confirming the mortalin decrease in 6-OHDA hemiparkinsonian rats, we tested whether inhibition of this protein was able to alter electrical neuronal activity in a corticostriatal brain slice preparation.
FPs were recorded from the striatum following activation of glutamatergic corticostriatal inputs. As shown in Figure 2A, bath application of the mortalin inhibitor MKT-077 induced a dose-dependent reduction of the FP amplitude ( $\mathrm{n}=8$ for each concentration). Notably, at the washout of the drug, this effect was irreversible up to an additional 30 minutes (data not shown). Although a 1-hour incubation of brain slices in $3 \mu \mathrm{M}$ MKT-077 had no effect on FP amplitude, $10 \mu \mathrm{M}$ and $30 \mu \mathrm{M}$ MKT-077 reduced the FP amplitude by $30.5 \% \pm 9 \%$ and $81.6 \% \pm 10 \%$, respectively, after 1 hour of application. 
The effect of the mortalin inhibitor MKT-077 was also investigated by utilizing intracellular recordings from electrophysiologically identified principal spiny neurons (MSNs). The main characteristics of these cells have been described in detail previously. ${ }^{39}$ These cells were silent at rest $(\mathrm{Vm}=-84 \pm 5 \mathrm{mV})$ and showed tonic firing activity during a long-duration depolarizing pulse. Five to 10 minutes from the onset of perfusion, $10 \mu \mathrm{M}$ MKT-077 induced a slow membrane depolarization, reaching a plateau at 25-30 minutes, when neuron membrane potential was -69.7 $\pm 3.6 \mathrm{mV}$ ( $\mathrm{n}=9$, Fig. $2 \mathrm{~B})$. Also in this case, the electrophysiological effect induced by the toxin was irreversible after its washout ( $\mathrm{n}=5$, data not shown).

To further characterize the response of MSNs to mortalin inhibition, whole-cell patch clamp recordings were performed. The mean holding current for these cells was $25.5 \pm 18.2 \mathrm{pA}\left(\mathrm{V}_{\text {hold }}=-80 \mathrm{mV}, \mathrm{n}=8\right)$. Bath application of $10 \mu \mathrm{M}$ MKT-077 produced a maximal inward current of $133 \pm 41 \mathrm{pA}(\mathrm{n}=8)$ after the onset of MKT-077 application (Fig. 2C), whose time course mimicked the membrane depolarization observed in current clamp experiments performed with sharp electrodes. Current-voltage plot showed that $10 \mu \mathrm{M}$ MKT-077 produces an inward current that reversed at about $-35 \mathrm{mV}$, suggesting the possible involvement of a mixed cationic conductance (Fig. 2D).

\section{Effect of Mortalin Inhibition in Corticostriatal Slice Preparations from 6-OHDA-Lesioned Rats}

Low mortalin levels were described previously in autoptic corticostriatal specimens from PD patients. ${ }^{19}$ In the present work, we observed a reduced mortalin level in the striata of 6-OHDA-treated rats. To test the hypothesis that inhibition of mortalin might further impair neuronal energetic metabolism in experimental PD, we focused our attention on the effects of MKT-077 in slice preparations obtained from 6-OHDA-lesioned rats. In either sham-operated or 6-OHDA animals, MKT-077 $(1-30 \mu \mathrm{M})$ reduced the FP amplitude in a dose-dependent manner (Fig. 3A). However, the reduction in FP amplitude was significantly larger in slices from 6-OHDA animals, where mortalin levels were impaired relative to sham animals $(P<.001, \mathrm{n}=6$ for each concentration; Fig. 3A,B $)$, revealing a larger sensitivity of striatal slices of 6-OHDA rats to mortalin inhibition with respect to sham and control animals.

\section{Effect of Mortalin Inhibition in Slices with Impaired Activity of Mitochondrial Complex I}

Experimental studies have reported that generalized complex I inhibition by the widely used natural pesticide rotenone causes mitochondrial dysfunction and
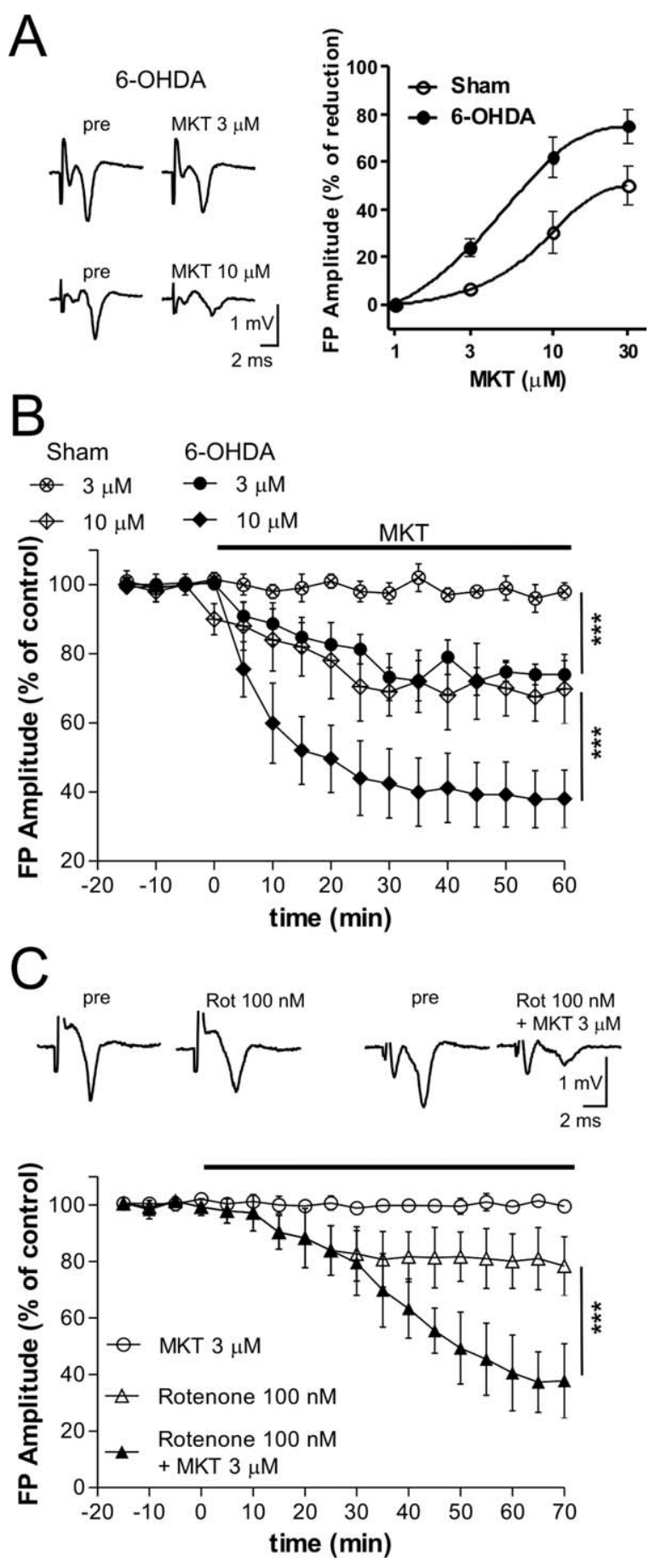

FIG. 3. Mortalin inhibition effects in the 6-OHDA and rotenone model of parkinsonism. A: Example traces of corticostriatal FP recorded from slices of 6-OHDA-lesioned rats in control conditions and in the presence of 3 and $10 \mu \mathrm{M}$ MKT-077 (left). Dose-response curves of the effect of MKT on FPs recorded in corticostriatal slices from 6-OHDAlesioned rats and from sham-operated rats (right). B: Time course of FPs recorded in slices from 6-OHDA and sham-operated rats in control conditions and after the application of 3 or $10 \mu \mathrm{M}$ MKT. C: Example of FP recordings from naive rats in control conditions and in the presence of $100 \mathrm{nM}$ rotenone or $100 \mathrm{nM}$ rotenone plus $3 \mu \mathrm{M}$ MKT. Time course showing the effect of $3 \mu \mathrm{M}$ MKT and $100 \mathrm{nM}$ rotenone bath applied in isolation and the significantly large FP reduction when $100 \mathrm{nM}$ rotenone plus $3 \mu \mathrm{M}$ MKT was coapplied in corticostriatal slices from naive rats $\left({ }^{\star \star \star} P<.001\right)$. 
damage of both nigral and striatal neurons in a pattern reminiscent of atypical parkinsonian syndromes such as progressive supranuclear palsy (PSP). ${ }^{40,41} \mathrm{We}$ verified whether inhibition of mortalin function affected the corticostriatal FP in the mitochondrial dysfunction model obtained by rotenone application. In fact, rotenone induced irreversible electrophysiological alterations in striatal neurons from the corticostriatal slice, reflecting neuronal death in a dose-dependent manner. ${ }^{35,42}$ As shown in Figure 3C, $100 \mathrm{nM}$ rotenone bath applied for 70 minutes produced only a mild reduction in the FP amplitude $(19.9 \% \pm 9.6 \%, \mathrm{n}=5)$. Interestingly, rotenone applied at the same concentration $(100 \mathrm{nM})$ produced a significantly larger effect on the FP amplitude in the presence of a dose of the mortalin inhibitor MKT-077 $(3 \mu \mathrm{M})$ that had no effect on the FP amplitude of naive rats when applied alone (Figs. 2A and 3C).

\section{Discussion}

\section{Major Findings}

In the present study there were 3 new major findings with both physiological and clinical relevance.

1. The first object of the study was to confirm the pathophysiological role of the mitochondrial heat shock protein mortalin in 6-OHDA-treated rats, a consolidated experimental model of PD. Proteomic analysis of striatal proteins revealed a significant difference in the expression of several proteins in 6-OHDA-treated rats relative to controls. Notably it enlightened low levels of mortalin compared with sham-operated animals.

2. As a second major target, we investigated the physiological function of mortalin in the striatum, a structure that is critically involved in the pathophysiology of PD and is particularly sensitive to mitochondrial dysfunction. Experiments performed in physiological conditions in the presence of the mortalin inhibitor MKT-0 $077^{26,27}$ showed a pivotal role of mortalin in controlling neuronal homeostasis. In fact, MKT-077 application produced a cell depolarization/inward current in all recorded striatal medium spiny neurons and a progressive loss of corticostriatal field potentials in all the slices analyzed, supporting the idea that within the striatum, at least medium spiny neurons are sensitive to mortalin inhibition.

3. Finally, we investigated the role of mortalin in maintaining neuronal function in striatal slices from 2 different models of PD. In slices obtained from 6-OHDA-treated rats, MKT-077 produced progressive impairment of striatal field potentials that was significantly more pronounced relative to that measured in slices from sham-operated animals. Furthermore, MKT-077 application enhanced the neural impairment of striatal field potentials produced by the application of a known dose of rotenone, a selective inhibitor of mitochondrial complex I.

\section{Proteomic Analysis in Physiological Conditions and in the Parkinsonian State}

Differential protein expression in 6-OHDA hemiparkinsonian rats was investigated by 2DE and LC-MS/ MS. The results obtained confirmed recently published observations. ${ }^{43}$ In particular, we found a statistically significant downregulation of 14-3-3 epsilon, 4-aminobutyrate (GABA) aminotransferase, neurofilament protein L, ubiquitin-conjugating enzyme E2N, and triosephosphate isomerase in 6-OHDA ipsilateral striata with respect to sham-operated controls. We could not find any significant difference between the 2 groups for the other proteins listed in the work by Park and colleagues. In this regard, note that in their investigation the proteomic analysis was performed 510 or 20 days post-6-OHDA injection, whereas in our study, the dissection of striatal tissue was done at least 45 days after injection. So it seems reasonable that some dissimilarities in protein expression may be a result of the different times of proteomic analysis.

Among the 19 differentially expressed proteins, we also found that mortalin was underexpressed in 6OHDA-treated rats relative to sham-operated controls. This finding confirms previous evidence demonstrating that mortalin is downregulated in different PD models as well as in the substantia nigra of PD patients. ${ }^{19}$ Given the potential involvement of mortalin expression in the onset of neurodegenerative diseases such as $\mathrm{PD},{ }^{44}$ attention was focused on this protein.

\section{Role of Mortalin in Physiological Conditions}

The effect of mortalin inhibition with MKT-077 was characterized by the electrophysiological activity of corticostriatal brain slices from control rats and 6OHDA-treated animals. In physiological conditions, mortalin inhibition with MKT-077 reduced the corticostriatal field potential in a dose-dependent manner. This effect was paralleled by a membrane depolarization/inward current recorded from single MSNs. Thus, the inhibition of mortalin with a bath application of MKT-077 induced alterations of electrophysiological properties in MSNs mimicking those previously demonstrated for rotenone, a mitochondrial complex I inhibitor. ${ }^{35}$ It can be hypothesized that disruption of mitochondrial homeostasis after mortalin inhibition may trigger a complex cascade of events mainly related to an increase in oxidative stress and protein 
misfolding, leading finally to irreversible changes in striatal electrical activity and possibly cell death.

\section{Role of Mortalin in Parkinsonian State}

The link between mortalin-induced mitochondrial dysfunction and alteration of electrophysiological activity was then studied in 6-OHDA-treated rats, which, as shown by proteomic analysis, had decreased levels of mortalin. Hemiparkinsonian rats were significantly more vulnerable to mortalin inhibition than were sham-operated animals, as shown by the greater reduction of field potentials in these animals. Finally, targeting mitochondria with the complex I inhibitor rotenone and using a relatively low concentration of this pesticide, we were able to show a reduction of FPs in corticostriatal slices that was increased by the concomitant application of a low concentration of MKT-077. Taken together, this evidence points to the potential involvement of mortalin in the pathogenetic process of PD. Mortalin has crucial roles in mitochondria, being an essential part of translocase systems ${ }^{45}$ and helping newly imported proteins during folding in mitochondria together with heat shock protein $60 .{ }^{46}$ Mortalin is also involved in patrolling for proteins to be degraded or rescued from misfolding, ${ }^{47}$ and it is also a biosensor of apoptotic stimuli, given its involvement in regulating the release of cytochrome $\mathrm{C}$ from mitochondria. ${ }^{48}$ Lack of mortalin in mitochondria may cause an imbalance of mitochondrial activities including electron transport and calcium uptake, which may lead to an increase of ROS production and alteration of calcium-related signaling. ${ }^{49}$

In addition, together with mortalin, other proteins involved in protection against oxidative stress were significantly reduced, such as isoforms of glutathioneS-transferase and cyclophilin A, supporting the hypothesis of global dysfunction in cellular systems against ROS in this PD model. ${ }^{50}$

An irreversible decrease in striatal electrical activity after mortalin inhibition could be seen as the physiological consequence of mitochondrial impairment, a situation that most likely would also happen in PD patients, in whom a mortalin decrease may contribute to mitochondrial dysfunction, finally leading to neuronal cell death.

Interestingly, morphological abnormalities, possibly revealing a neurodegenerative process, have been reported not only in the substantia nigra pars compacta but also in striatal spiny neurons of $\mathrm{PD}$ patients $^{51,52}$ and in experimental models of PD. ${ }^{53}$ These changes are mainly expressed at the dendritic level ${ }^{51,52}$ and cause selective elimination of glutamatergic synapses. ${ }^{53}$ Neurotoxicity and the enhancement of oxidative stress triggered by 6-OHDA treatment might determine an impairment of the mitochondrial metabolism in DA and striatal neurons also affecting mortalin function. Thus, although DA neurons seem to be primarily injured by these factors, it is possible that the impaired mortalin function observed at the striatal level in PD contributes to these morphological changes, leading to abnormal processing of glutamatergic information originating from the cortex and thus acting as a concomitant factor that might lead to neuronal death. Accordingly, in slices from 6-OHDAtreated rats and in the rotenone model of $\mathrm{PD}$, acute inhibition of mortalin by MKT-077 quickly worsened cellular global homeostasis and produced the observed electrophysiological death. However, we cannot exclude that mortalin inhibition represents only a result of the neurodegenerative process rather than a major contributing factor. For this reason, we believe that treatments aimed at preserving mortalin function in PD models might be a possibility to gain insight into the mechanisms by dissecting the distinct actions of nigral versus striatal neurons in this pathological condition.

Acknowledgment: We thank C. Spaccatini for his excellent technical support.

\section{References}

1. Lang AE, Lozano AM. Parkinson's disease. First of two parts. N Engl J Med. 1998;339:1044-1053.

2. Janetzky B, Hauck S, Youdim MB, et al.Unaltered aconitase activity, but decreased complex I activity in substantia nigra pars compacta of patients with Parkinson's disease. Neurosci Lett. 1994; 169:126-128.

3. Orth M, Schapira AH. Mitochondrial involvement in Parkinson's disease. Neurochem Int. 2002;40:533-541.

4. Schapira AH, Cooper JM, Dexter D, Clark JB, Jenner P, Marsden CD. Mitochondrial complex I deficiency in Parkinson's disease. J Neurochem. 1990;54:823-827.

5. Greenamyre JT, Betarbet R, Sherer TB. The rotenone model of Parkinson's disease: genes, environment and mitochondria. Parkinsonism Relat Disord. 2003;9(Suppl 2):S59-S64.

6. Langston JW, Ballard P, Tetrud JW, Irwin I. Chronic Parkinsonism in humans due to a product of meperidine-analog synthesis. Science. 1983;219:979-980.

7. Di Filippo M, Chiasserini D, Tozzi A, Picconi B, Calabresi P. Mitochondria and the link between neuroinflammation and neurodegeneration. J Alzheimers Dis. 2010;20(Suppl 2):S369-S379.

8. Przedborski S, Jackson-Lewis V, Djaldetti R, et al.The parkinsonian toxin MPTP: action and mechanism. Restor Neurol Neurosci. 2000;16:135-142.

9. Sherer TB, Betarbet R, Testa CM, et al.Mechanism of toxicity in rotenone models of Parkinson's disease. J Neurosci. 2003;23: 10756-10764.

10. Glinka YY, Youdim MB. Inhibition of mitochondrial complexes I and IV by 6-hydroxydopamine. Eur J Pharmacol. 1995;292: 329-332.

11. Ben-Shachar D, Zuk R, Glinka Y. Dopamine neurotoxicity: inhibition of mitochondrial respiration. J Neurochem. 1995;64:718-723.

12. Deocaris CC, Kaul SC, Wadhwa R. From proliferative to neurological role of an hsp70 stress chaperone, mortalin. Biogerontology. 2008;9:391-403.

13. Calabrese V, Scapagnini G, Ravagna A, Giuffrida Stella AM, Butterfield DA. Molecular chaperones and their roles in neural cell differentiation. Dev Neurosci. 2002;24:1-13.

14. Endo T, Yamano K. Multiple pathways for mitochondrial protein traffic. Biol Chem. 2009;390:723-730. 
15. Becker J, Craig EA. Heat-shock proteins as molecular chaperones. Eur J Biochem. 1994;219:11-23.

16. Falsone SF, Kungl AJ, Rek A, Cappai R, Zangger K. The molecular chaperone Hsp90 modulates intermediate steps of amyloid assembly of the Parkinson-related protein alpha-synuclein. J Biol Chem. 2009;284:31190-31199.

17. Tantucci M, Mariucci G, Taha E, et al.Induction of heat shock protein 70 reduces the alteration of striatal electrical activity caused by mitochondrial impairment. Neuroscience. 2009;163: $735-740$.

18. Geissler A, Rassow J, Pfanner N, Voos W. Mitochondrial import driving forces: enhanced trapping by matrix Hsp70 stimulates translocation and reduces the membrane potential dependence of loosely folded preproteins. Mol Cell Biol. 2001;21:7097-7104.

19. Jin J, Hulette C, Wang Y, et al.Proteomic identification of a stress protein, mortalin/mthsp70/GRP75: relevance to Parkinson disease. Mol Cell Proteomics. 2006;5:1193-1204.

20. Xu L, Voloboueva LA, Ouyang Y, Emery JF, Giffard RG. Overexpression of mitochondrial Hsp70/Hsp75 in rat brain protects mitochondria, reduces oxidative stress, and protects from focal ischemia. J Cereb Blood Flow Metab. 2009;29:365-374.

21. Shi M, Jin J, Wang Y, et al.Mortalin: a protein associated with progression of Parkinson disease?J Neuropathol Exp Neurol. 2008; 6rogression $117-124$.

22. Jin J, Li GJ, Davis J, et al.Identification of novel proteins associated with both alpha-synuclein and DJ-1. Mol Cell Proteomics. 2007;6:845-859.

23. Liu Y, Liu W, Song XD, Zuo J. Effect of GRP75/mthsp70/PBP74/ mortalin overexpression on intracellular ATP level, mitochondrial membrane potential and ROS accumulation following glucose deprivation in PC12 cells. Mol Cell Biochem. 2005;268:45-51.

24. Van Laar VS, Dukes AA, Cascio M, Hastings TG. Proteomic analysis of rat brain mitochondria following exposure to dopamine quinone: implications for Parkinson disease. Neurobiol Dis. 2008; 29:477-489.

25. Van Laar VS, Mishizen AJ, Cascio M, Hastings TG. Proteomic identification of dopamine-conjugated proteins from isolated rat brain mitochondria and SH-SY5Y cells. Neurobiol Dis. 2009;34: 487-500.

26. Deocaris CC, Widodo N, Shrestha BG, et al.Mortalin sensitizes human cancer cells to MKT-077-induced senescence. Cancer Lett. 2007;252:259-269.

27. Widodo N, Deocaris CC, Kaur K, et al.Stress chaperones, mortalin, and pex $19 \mathrm{p}$ mediate 5 -aza- $2^{\prime}$ deoxycytidine-induced senescence of cancer cells by DNA methylation-independent pathway. J Gerontol. 2007;62:246-255.

28. Picconi B, Centonze D, Hakansson K, et al.Loss of bidirectional striatal synaptic plasticity in L-DOPA-induced dyskinesia. Nat Neurosci. 2003;6:501-506.

29. Paxinos G, Watson C.The Rat Brain in Stereotaxic Coordinates.Sydney, Australia:Academic Press;1986.

30. Schwarting RKW, Huston JP. Unilateral 6-hydroxy-dopamine lesions of mesostriatal dopamine neurons and their physiological sequelae. Prog Neurobiol. 1996;49:215-266.

31. Bradford MM. A rapid and sensitive method for the quantitation of microgram quantities of protein utilizing the principle of protein-dye binding. Anal Biochem. 1976;72:248-254.

32. Puxeddu E, Susta F, Orvietani PL, et al.Identification of differentially expressed proteins in papillary thyroid carcinomas with V600E mutation of BRAF. Proteomics Clin Appl. 2007;1:672-680.

33. Susta F, Chiasserini D, Fettucciari K, et al.Protein expression changes induced in murine peritoneal macrophages by Group B Streptococcus. Proteomics. 2010;10:2099-2012.
34. Calabresi P, Saiardi A, Pisani A, et al.Abnormal synaptic plasticity in the striatum of mice lacking dopamine D2 receptors. J Neurosci. 1997; 17:4536-4544.

35. Costa C, Belcastro V, Tozzi A, et al.Electrophysiology and pharmacology of striatal neuronal dysfunction induced by mitochondrial complex I inhibition. J Neurosci. 2008;28:8040-8052.

36. Norgren N, Rosengren L, Stigbrand T. Elevated neurofilament levels in neurological diseases. Brain Res. 2003;987:25-31.

37. Mazzio EA, Reams RR, Soliman KF. The role of oxidative stress, impaired glycolysis and mitochondrial respiratory redox failure in the cytotoxic effects of 6-hydroxydopamine in vitro. Brain Res. 2004;1004:29-44.

38. Massignan T, Casoni F, Basso M, et al.Proteomic analysis of spinal cord of presymptomatic amyotrophic lateral sclerosis G93A SOD1 mouse. Biochem Biophys Res Commun. 2007;353:719-725.

39. Calabresi P, Centonze D, Pisani A, et al.Striatal spiny neurons and cholinergic interneurons express differential ionotropic glutamatergic responses and vulnerability: implications for ischemia and Huntington's disease. Ann Neurol. 1998;43:586-597.

40. Hoglinger GU, Lannuzel A, Khondiker ME, et al.The mitochondrial complex I inhibitor rotenone triggers a cerebral tauopathy. J Neurochem. 2005;95:930-939.

41. Centonze D, Prosperetti C, Barone I, et al.NR2B-containing NMDA receptors promote the neurotoxic effects of 3-nitropropionic acid but not of rotenone in the striatum. Exp Neurol. 2006; 202:470-479.

42. Tozzi A, Tscherter A, Belcastro V, et al.Interaction of A2A adenosine and D2 dopamine receptors modulates corticostriatal glutamatergic transmission. Neuropharmacology. 2007;53:783-789.

43. Park B, Yang J, Yun N, Choe KM, Jin BK, Oh YJ. Proteomic analysis of expression and protein interactions in a 6-hydroxydopamine-induced rat brain lesion model. Neurochem Int. 2010;57: 16-32.

44. Witt SN. Hsp70 molecular chaperones and Parkinson's disease. Biopolymers. 2010;93:218-228.

45. Horst M, Oppliger W, Rospert S, Schonfeld HJ, Schatz G, Azem A. Sequential action of two hsp70 complexes during protein import into mitochondria. EMBO J. 1997;16:1842-1849.

46. Deocaris CC, Kaul SC, Wadhwa R. On the brotherhood of the mitochondrial chaperones mortalin and heat shock protein 60 . Cell Stress Chaperones. 2006;11:116-128.

47. Wagner I, Arlt H, van Dyck L, Langer T, Neupert W. Molecular chaperones cooperate with PIM1 protease in the degradation of misfolded proteins in mitochondria. EMBO J. 1994;13:5135-5145.

48. Taurin S, Seyrantepe V, Orlov SN, et al.Proteome analysis and functional expression identify mortalin as an antiapoptotic gene induced by elevation of $[\mathrm{Na}+] \mathrm{i} /[\mathrm{K}+] \mathrm{i}$ ratio in cultured vascular smooth muscle cells. Circ Res. 2002;91:915-922.

49. Schwarzer C, Barnikol-Watanabe S, Thinnes FP, Hilschmann N. Voltage-dependent anion-selective channel (VDAC) interacts with the dynein light chain Tctex1 and the heat-shock protein PBP74. Int J Biochem Cell Biol. 2002;34:1059-1070.

50. Smith MP, Cass WA. Oxidative stress and dopamine depletion in an intrastriatal 6-hydroxydopamine model of Parkinson's disease. Neuroscience. 2007;144:1057-1066.

51. Braak H, Del Tredici K. Nervous system pathology in sporadic Parkinson disease. Neurology. 2008;70:1916-1925.

52. Stephens B, Mueller AJ, Shering AF, et al.Evidence of a breakdown of corticostriatal connections in Parkinson's disease. Neuroscience. 2005;132:741-754.

53. Day M, Wang Z, Ding J, et al.Selective elimination of glutamatergic synapses on striatopallidal neurons in Parkinson disease models. Nat Neurosci. 2006;9:251-259. 